\title{
Analisis Laju Aliran Udara dan Laju Aliran Massa Bahan Bakar Terhadap Beban Pembakaran Sampah pada Incinerator Berbahan Bakar Limbah Oli Bekas
}

\author{
(1) Junaidi, ${ }^{(2) *}$ Eddy Kurniawan, ${ }^{(3)}$ Abdika Lasmana \\ ${ }^{(1)}$ Program Studi Teknik Elektro, Universitas Tanjungpura Jl. Prof. Dr. Hadari Nawawi, Pontianak \\ ${ }^{(2,3)}$ Program Studi Teknik Mesin, Universitas Tanjungpura Jl. Prof. Dr. Hadari Nawawi, Pontianak \\ *Email: eddy_kurniawan@teknik.untan.ac.id
}

Diterima: 08.05.2021, Disetujui: 29.05.2021, Diterbitkan: 30.05.2021

\begin{abstract}
The amount of household waste and B3 waste from used oil always increases with the increase in population and vehicles. This used oil waste is used as an energy source. The purpose of this study was to find the highest temperature resulting from variations in air flow rate and mass flow rate of used oil fuel for burning waste in the incinerator room using a burner furnace by conducting several experiments with variations in air velocity of $10.4 \mathrm{~m} / \mathrm{s}(B 1), 13.4 \mathrm{~m} / \mathrm{s}$ (B2) and $14.3 \mathrm{~m} / \mathrm{s}$ (B3) and the fuel flow rate is $0.00408 \mathrm{l} / \mathrm{s}(\mathrm{A1})$ and $0.00838 \mathrm{l} / \mathrm{s}$ (A2) with fuel valve opening $1 / 2$ and $1 / 4$ of this study using experimental methods. The results obtained from the test showed that the highest temperature of the burner furnace was $1021.5^{\circ} \mathrm{C}$ in the $A 2-B 3$ variation of the experiment with 45 minutes of time and the lowest temperature was obtained in the A1-B1 variation of the experiment, which was $840.5^{\circ} \mathrm{C}$ at the same time. In the incinerator test, combustion of dry leaf waste weighing $8 \mathrm{~kg}$ can burn in 20 minutes with a burner furnace temperature ratio of $712.3^{\circ} \mathrm{C}$ and an incinerator chamber of $443.2^{\circ} \mathrm{C}$ and a combustion rate of $24.24 \mathrm{~kg} / \mathrm{hour}$, the yield of combustion residue is $3.06 \%$ and incinerator combustion efficiency $96.94 \%$ and fuel consumption used is 0.4 liters.
\end{abstract}

Keywords: Waste, incinerator, burner furnance

\begin{abstract}
ABSTRAK
Jumlah limbah rumah tangga dan limbah B3 dari oli bekas selalu meningkat seiring dengan peningkatan jumlah penduduk dan kendaraan. Limbah oli bekas ini digunakan sebagai sumber energi. Tujuan dari penelitian ini adalah untuk mencari temperatur tertinggi yang dihasilkan dari variasi laju aliran udara dan laju aliran massa bahan bakar oli bekas untuk pembakaran sampah diruang incinerator menggunakan tungku burner dengan melakukan beberapa percobaan dengan variasi kecepatan udara $10,4 \mathrm{~m} / \mathrm{s}$ (B1), 13,4 m/s (B2) dan 14,3 m/s (B3) dan laju alir bahan bakar 0,00408 1/s (A1) dan 0,00838 1/s (A2) dengan bukaan katup bahan bakar $1 / 2$ dan $1 / 4$ penelitian ini menggunakan metode eksperimental (percobaan). Hasil yang diperoleh dari pengujian menunjukkan bahwa suhu tertinggi tungku burner adalah $1021,5^{\circ} \mathrm{C}$ pada variasi percobaan A2-B3 dengan waktu 45 menit dan suhu terendah diperoleh pada variasi percobaan $\mathrm{A} 1-\mathrm{B} 1$ yaitu $840,5^{\circ} \mathrm{C}$ pada waktu yang bersamaan. Pada pengujian insinerator, pembakaran sampah daun kering seberat $8 \mathrm{~kg}$ dapat terbakar dalam waktu 20 menit dengan perbandingan temperatur tungku burner sebesar $712,3^{\circ} \mathrm{C}$ dan ruang ruang incinerator $443,2^{\circ} \mathrm{C}$ dan laju pembakaran $24,24 \mathrm{~kg} / \mathrm{jam}$ rendemen sisa pembakaran $3,06 \%$ dan efisiensi pembakaran incinerator $96,94 \%$ dan konsumsi bahan bakar yang digunakan 0,4 liter.
\end{abstract}

Kata Kunci: Sampah, incinerator, tungku burner

\section{Pendahuluan}

Sampah merupakan bahan tak terpakai yang dibuang dari hasil kegiatan manuisa, maupun dari alam yang sifatmya tidak mempunyai nilai ekonomi. Istilah limbah seperti sampah rumah tangga dan industri yang berupa sampah organik dan juga sampah anorganik maupun sampah B3 (bahan beracun dan berbahaya). penelitian (Ratman \& 
Syafrudin, 2007) dengan menganalisa pengolahan limbah B3 menggunakan incinerator. Metode pengurangan sampah atau limbah dapat dilakukan dengan cara 3R (Reuse, Recycle dan Reduce). Karena dengan cara $3 \mathrm{R}$ ialah paling tepat dalam mengatasi pengurangan sampah yang ada di kota maupun suatu wilayah karena dapat mengurangi timbulan sampah sebesar 15-20\% (Nurhayati, 2013) dan penelitian (Lolo, 2014) dengan menganalisis penggunaan incinerator di pengelolaan sampah di kota Merauke. Dengan hal tersebut diharuskan ada pengelolaan sampah yang baik dan ramah lingkungan agar sampah yang dikelola tidak merusak lingkungan sekitar. Pada saat proses pembakaran sampah sangat membahayakan bagi kesehatan orang yang berada disekitarnya karena gas hasil pembakaran (Jamaluddin, 2016). Pembakaran di ruang terbuka bisa menyebabkan pembakaran yang tidak terkontrol dan juga bisa mengakibatkan gangguan pada lingkungan sekitar adapun faktor yang mempunyai peranan penting dalam insinerasi ialah temperatur dan lama pembakaran sampah (Latief, 2010). Permasalahan tersebut umumnya sering dilakukan oleh kalangan masyarakat karena merasa terganggu dengan sampah yang tertimbun dan juga memakai tempat. Solusi dalam penanganan sampah tersebut berupa pembakaran dengan menggunakan alat atau instalasi alat pembakar sampah mini incinerator (Margono \& Rahardjo, 2011) melakukan penelitian rancang bangun incinerator untuk tungku pembakaran sampah radio aktif.

Penggunaan alat tersebut dapat mengurangi dampak negatif dari proses pembakaran seperti asap, bau, radiasi dan panas juga upaya pemanfaatan energi panas hasil dari pembakaran sampah tersebut. Suhu yang dapat dihasilkan pada pembakaran incinerator mencapai $500-1000^{\circ} \mathrm{C}$ sehingga sampah menjadi abu. Dari hasil penelitian sebelumnya mengenai incinerator ini terdapat dua ruang bakar yaitu ruang bakar tingkat kedua dan ruang bakar utama. Ruang bakar utama suhu mencapai $800^{\circ} \mathrm{C}-1.000^{\circ} \mathrm{C}$ dengan menggunakan burner dan blower. Sedangkan di ruang bakar tingkat kedua suhu mencapai $1100^{\circ} \mathrm{C}$. Incinerator ini memerlukan energi besar karena burner yang dipakai dalam pengoperasiannya selalu dinyalakan (steady) sehingga memakai bahan bakar yang banyak (Kurdi, 2017) juga dari penelitian (sumingkrat dkk. 2014) yang mengelola limbah cair dengan limbah padat abu dari hasil pembakaran incinerator.

Dari penelitian yang berjudul "Pengaruh Kecepatan Udara Terhadap Pembakaran Oli Bekas Menggunakan Automizing Burner Untuk Peleburan Aluminium" (Supriyanto, 2007) dapat diketahui kecepatan udaranya pengaruhnya ke pembakaran oli bekas juga minyak jelantah pada rasio bahan bakar dan udara. Panas hasil dari pembakaran ini energinya dimanfaatkan untuk meleburkan alumunium. Pembakarannya menggunakan air automizing burner, dengan kecepatan variasi udaranya $0,2,4,6,8,10$ dan $12 \mathrm{~m} /$ sdari blower. Dengan campuran $70 \%$ bahan bakar dan $30 \%$ oli bekas. Pada saat pengujiannya, warna api dan panjang api dilihat lalu diamati secara visual lalu diukur ketika temperatur nyala stabil dan diukur. Energi dari penggunaan oli bekas untuk peleburan alumunium dilihat dari temperatur di tungku peleburan lalu konsumsi dari bahan bakar serta waktu dari alumunium tersebut dapat mencair. Sedangkan dari penelitian lainnya yang berjudul "Pemanfaatan Oli Bekas Dengan Pencampuran Minyak Tanah Sebagai Bahan Bakar Pada Automizing Burner" (Raharjo, 2009) dilakukan untuk mengolah oli bekas yaitu dengan cara destilasi lalu memanaskannya ditemperatur $2000^{\circ} \mathrm{C}$ yang bertujuan sebagai penguapan zat cair pada oli. Oli dicampur dengan minyak tanah dan kadarnya ialah $10 \%, 20 \%, 30 \%$ dan $40 \%$ yang digunakan sebagai bahan bakar auotomizing burner dalam tekanan udara $8 \mathrm{~m} / \mathrm{s}$. Hasilnya kadar campuran dari minyak tanah yang tinggi dapat menurunkan viskositas dan meningkatkan nilai kalor dari bahan bakar temperatur pembakaran suhu tertingginya yaitu $1386^{\circ} \mathrm{C}$ untuk campuran $30 \%$ dan yang terendah $10 \%$ akan tetapi campuran $30 \%$ menunjukan penggunaan bahan bakar yang tinggi. Selain itu penelitian dengan judul “ Pengaruh Tekanan Udara Terhadap Sifat Pembakaran Minyak Jelantah Menggunakan Vaporizing Burner untuk Peleburan Alumunium" (Widhiasto, 2010).

Tujuan dari penelitian ini adalah untuk mengetahui temperatur maksimum , minimum dan waktu pembakaran yang dihasilkan dari 
percobaan variasi laju aliran massa udara dan bahan bakar terhadap pembakaran sampah diruang incinerator dan efisiensi dari incinerator. Selain itu dari hasil percobaan ini ingin melihat efisiensi dari proses pembakaran pada incinerator.

\section{Bahan dan Metode}

Pada penelitian kali ini metode yang digunakan ialah metode dengan eksperimen langsung bahan yang digunakan tungku burner menggunakan blower listrik dan ruang pembakaran incinerator untuk pengambilan data laju aliran massa udara menggunakan alat ukur anemometer diletakkan diujung pipa output dari blower listrik yang ditunjukan pada Gambar 1. untuk mencari kecepatan udara terlebih dahulu.
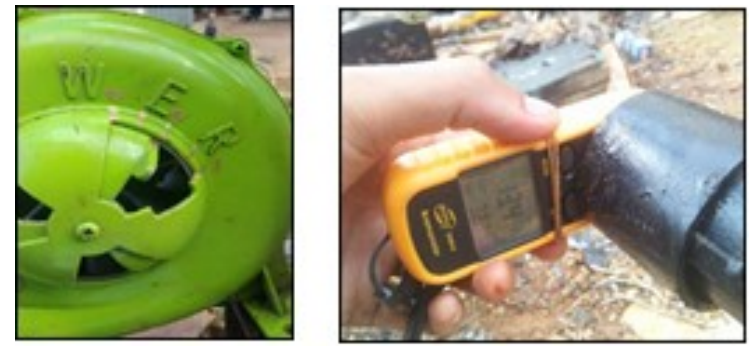

Gambar 1. Pengukuran kecepatan udara

Pada pengukuran kecepatan udara didapat data yaitu sebagai berikut :

Tabel 1. Data pengukuran kecepatan udara

\begin{tabular}{cc} 
No & Kecepatan udara $\left(\mathrm{V}_{\text {air }}\right)$ \\
\hline 1 & $10,4 \mathrm{~m} / \mathrm{s}$ \\
\hline 2 & $13,4 \mathrm{~m} / \mathrm{s}$ \\
\hline 3 & $14,3 \mathrm{~m} / \mathrm{s}$
\end{tabular}

Maka untuk mencari laju aliran massa udara ialah sebagai berikut :

$$
\dot{m}=\rho_{\text {air }} \cdot V_{\text {air }} \cdot A
$$

dengan :

$\dot{m} \quad=$ laju aliran massa dari udara $(\mathrm{kg} / \mathrm{s})$

$\rho_{\text {air }}=$ massa jenis dari udara $\left(\mathrm{kg} / \mathrm{m}^{3}\right)$

$V_{\text {air }}=$ laju kecepatan udara $(\mathrm{m} / \mathrm{s})$

$\mathrm{A}=$ luas penampang yang dilalui $\left(\mathrm{m}^{2}\right)$

Untuk mencari laju aliran massa bahan bakar oli bekas terlebih dahulu mencari debit aliran bahan bakar oli bekas menggunakan alat ukur gelas ukur selanjutnya melakukan perhitungan laju aliran massa dari bahan bakar yaitu sebagai berikut :

$$
\dot{m}=\frac{\rho x \text { Qdebit }}{1000}
$$

dengan :

$\dot{m}=$ laju aliran massa dai udara $(\mathrm{kg} / \mathrm{s})$

$\rho=$ massa jenis dari udara $\left(\mathrm{kg} / \mathrm{m}^{3}\right)$

$\mathrm{Q}_{\text {debit }}=$ debit aliran bahan bakar $(1 / \mathrm{s})$

Adapun data dari hasil pengukuran didapat sebagai berikut :

Tabel 2. Data volume,debit dan laju aliran massa dari bahan bakar

\begin{tabular}{cccc}
\hline Volume & $\begin{array}{c}\text { Bukaan } \\
\text { Kran }\end{array}$ & Debit & $\begin{array}{c}\text { Laju Aliran } \\
\text { Massa } \\
\text { Bahan } \\
\text { Bakar (m) }\end{array}$ \\
\hline $\begin{array}{c}0,245 \\
\mathrm{ml}\end{array}$ & $1 / 4$ & $\begin{array}{c}0,00408 \\
1 / \mathrm{s}\end{array}$ & $\begin{array}{c}3,54144 \times \\
10^{-3} \mathrm{~kg} / \mathrm{s}\end{array}$ \\
\hline $\begin{array}{c}0,503 \\
\mathrm{ml}\end{array}$ & $1 / 2$ & $\begin{array}{c}0,00838 \\
1 / \mathrm{s}\end{array}$ & $\begin{array}{c}7,27384 \times \\
10^{-3} \mathrm{~kg} / \mathrm{s}\end{array}$ \\
\hline
\end{tabular}

Dalam proses penelitian kali ini langkalangkah dalam pengambilan data juga sebagai prosedur awal yaitu pengoperasian alat pada tungku burner sebelum melakukan pengujian ke incinerator. Adapun langkah-langkahnya sebagai berikut :

1. Pertama-tama sebelum melakukan proses pembakaran pada tungku burner adalah mengambil data awal yaitu kecepatan udara $(\mathrm{m} / \mathrm{s})$ dan debit bahan bakar (1/s) pada bukaan kran.

2. Pada proses pengambilan data kecepatan udara $(\mathrm{m} / \mathrm{s})$ dengan menghidupkan blower dan mengatur kecepatannya dengan bukaan katup inlet.

3. Mengisi bahan bakar oli bekas pada tanki bahan bakar dan memasang perangkat alat ukur thermometer type K pada burner lalu menyiapkan jenis sampah yang akan dibakar.

4. Selanjutnya melakukan pembakaran awal di tungku burner selama kurang lebih 5 menit menggunakan kayu bakar dan bensin yang dicampur oli agar nyala apinya stabil. 
5. Setelah nyala api ditungku stabil, hidupkan blower dan buka kran bahan bakar untuk menguji tungku burner apakah sudah bisa melakukan pengujian dengan variasi laju aliran massa udara dan laju aliran massa dari bahan bakar dengan data pada tabel sebagai berikut :

6.

Tabel 3. Tabel pengambilan data dari beberapa variasi percobaan

\begin{tabular}{cccc}
$\begin{array}{c}\text { Variasi } \\
\text { Percobaan }\end{array}$ & 1 & 2 & 3 \\
\hline $\begin{array}{c}\text { A ( debit } \\
\text { bahan bakar } \\
\text { ) }\end{array}$ & 0,00408 & 0,00838 & - \\
$1 / \mathrm{s}$ & $1 / \mathrm{s}$ & \\
\hline $\begin{array}{c}\text { B } \\
\text { (kecepatan } \\
\text { udara ) }\end{array}$ & $10,4 \mathrm{~m} / \mathrm{s}$ & $13,4 \mathrm{~m} / \mathrm{s}$ & $14,3 \mathrm{~m} / \mathrm{s}$ \\
\hline
\end{tabular}

Maka dari tabel diatas diperoleh keterangan variasi percobaan sebagai berikut:

A1-B1 : Variasi percobaan dengan debit bahan bakar $0,00408 \mathrm{l} / \mathrm{s}$ dan $10,4 \mathrm{~m} / \mathrm{s}$ kecepatan udara.

A1-B2 : Variasi percobaan dengan debit bahan bakar $0,00408 \mathrm{l} / \mathrm{s}$ dan $13,4 \mathrm{~m} / \mathrm{s}$ kecepatan udara.

A1-B3 : Variasi percobaan dengan debit bahan bakar $0,00408 \mathrm{l} / \mathrm{s}$ dan $14,3 \mathrm{~m} / \mathrm{s}$ kecepatan udara.

A2-B1 : Variasi percobaan dengan debit bahan bakar $0,00838 \mathrm{l} / \mathrm{s}$ dan $10,4 \mathrm{~m} / \mathrm{s}$ kecepatan udara.

A2-B2 : Variasi percobaan dengan debit bahan bakar $0,008381 / \mathrm{s}$ dan $13,4 \mathrm{~m} / \mathrm{s}$ kecepatan udara.

A2-B3 : Variasi percobaan dengan debit bahan bakar $0,00838 / \mathrm{s}$ dan $14,3 \mathrm{~m} / \mathrm{s}$ kecepatan udara.

Pada tahap proses kerja dari incinerator ini ialah tahap dimana prosedur melakukan pengujian pembakaran sampah. Adapun prosedur dari proses pembakaran sampah adalah sebagai berikut :

1. Limbah yang dipilih ialah sampah daun kering dan sampah plastik kemudian masing-masing sampah yang berbeda berdasarkan jenisnya dimasukkan ke dalam tungku pembakaran ruang incinerator sampai batas kapasitas ruang pembakaran antara 8 - $15 \mathrm{~kg}$ sampah.
2. Sampah dibakar menggunakan burner yang berbahan bakar limbah oli bekas yang terlebih dahulu dipanaskan kurang lebih 5 menit lalu api masuk melalui lubang dibawah.

3. Setelah proses pembakaran sudah stabil yaitu pada temperatur burner dan pada asap pembakaran sudah mulai keluar dari cerobong asap selanjutnya menghidupkan pompa air diruang filterisasi.

4. Mengukur temperatur ruang chamber menggunakan thermo infrared $H W 600$. Pengukuran dilakukan di titik yang telah ditentukan yaitu ruang chamber, cerobong asap dan ruang filterisasi.

5. Untuk pengukuran di tungku burner menggunakan Thermocouple TM - 902C.

6. Saat pembakaran, sampah yang dibakar habis dan apinya mengecil, maka burner di hidupkan kembali dengan mengatur bukaan katup inlet blower.

7. Button ash / rendemen bekas pembakaran dikeluarkan lewat Pintu yang terletak pada bagian bawah.

8. Fly ash / asap dari sisa pembakaran dialirkan ke ruang filterisasi asap.

9. Setelah rendemen bekas pembakaran sudah dibersihkan selanjutnya dilakukan proses pembakaran sampah baru.

Adapun rumus yang digunakan untuk mencari parameter uji kerja incinerator sebagai berikut :

a. Laju pembakaran

$$
\mathrm{Bbt}=\frac{\mathrm{m}(\mathrm{kg})}{\mathrm{t}(\mathrm{jam})}
$$

Dengan :

$\mathrm{B}_{\mathrm{bt}}=$ laju pembakaran dari sampah

( $\mathrm{kg} / \mathrm{jam})$

$\mathrm{m}$ = massa sampah yang akan dibakar

$(\mathrm{kg})$

$\mathrm{t}=$ waktu proses lama pembakaran (jam)

b. Rendemen Arang

Arang (\%) $=\frac{\text { Bobot arang }}{\text { Bobot sampah }} \times 100 \%$

c. Rendemen $\mathrm{Abu}$

$$
\text { Abu }(\%)=\frac{\text { Bobot abu }}{\text { Bobot sampah }} \times 100 \%
$$

d. Konsumsi Bahan Bakar 
$F C$ : volume bahan bakar awal - volume bahan bakar akhir

e. Efesiensi Alat

Efesiensi alat $(\%)=(100 \%-(\mathrm{A}(\%)+\mathrm{B}(\%))$

Dengan :

$$
\begin{aligned}
& \text { A : Rendemen Arang (\%) } \\
& \text { B : Rendemen Abu (\%) }
\end{aligned}
$$

\section{Hasil dan Pembahasan}

Pengujian pada tungku burner didapat data sebagai berikut:

Tabel 4. Kecepatan udara, massa jenis udara, luas penampang dan laju aliran massa udara

\begin{tabular}{ccccc}
\hline $\begin{array}{c}\text { Kecepatan } \\
\text { udara } \\
\text { (Vair) }\end{array}$ & $\begin{array}{c}\text { Kecepatan } \\
\text { blower }\end{array}$ & $\rho_{\text {air }}$ & $\begin{array}{c}\text { Luas } \\
\text { penampang } \\
\text { Pipa (A) }\end{array}$ & $\begin{array}{c}\text { Laju } \\
\text { aliran } \\
\text { massa } \\
\text { udara } \\
(\dot{m})\end{array}$ \\
\hline $10,4 \mathrm{~m} / \mathrm{s}$ & Rendah & $\begin{array}{c}1,2 \\
\mathrm{~kg} / \mathrm{m}^{3}\end{array}$ & $0,00202 \mathrm{~m}^{2}$ & $\begin{array}{c}0,0252 \\
\mathrm{~kg} / \mathrm{s}\end{array}$ \\
\hline $13,4 \mathrm{~m} / \mathrm{s}$ & Sedang & $\begin{array}{c}1,2 \\
\mathrm{~kg} / \mathrm{m}^{3}\end{array}$ & $0,00202 \mathrm{~m}^{2}$ & $\begin{array}{c}0,0324 \\
\mathrm{~kg} / \mathrm{s}\end{array}$ \\
\hline $14,3 \mathrm{~m} / \mathrm{s}$ & Tinggi & $\begin{array}{c}1,2 \\
\mathrm{~kg} / \mathrm{m}^{3}\end{array}$ & $0,00202 \mathrm{~m}^{2}$ & $\begin{array}{c}0,0346 \\
\mathrm{~kg} / \mathrm{s}\end{array}$ \\
\hline
\end{tabular}

\section{Hasil pengujian temperatur burner}

pengujian dilakukan selama 45 menit menggunakan alat ukur thermometer digital TM-902C dengan meletakkan ujung sensor probe thermometer ke dalam tungku. Pengukuran tungku burner pada Gambar 2, dibawah ini :

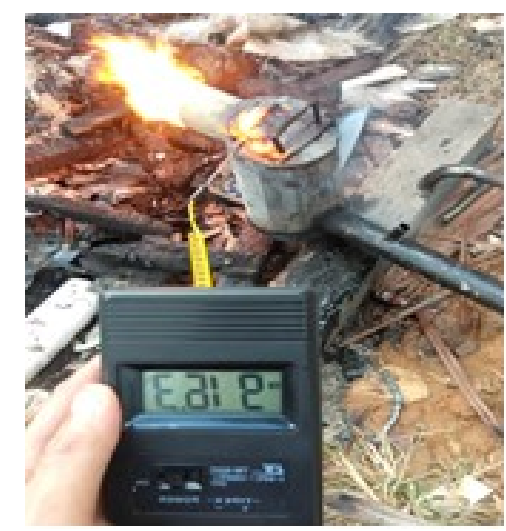

Gambar 2. Pengukuran temperatur tungku burner
Pengujian temperatur tungku burner didapat data temperatur tertinggi dan terendah pada 2 pengujian A1-B1, dan A2-B3. Adapun hasilnya ditunjukan pada Tabel 5 dan Tabel 6 ialah sebagai berikut :

Tabel 5. Temperatur rata-rata burner dengan variasi percobaan A1-B1

\begin{tabular}{ccc}
\hline Percobaan & $\begin{array}{c}\text { Waktu } \\
\text { (menit) }\end{array}$ & $\begin{array}{c}\text { Temperatur } \\
\text { rata-rata } \\
\text { burner } \\
\left({ }^{\circ} \mathrm{C}\right)\end{array}$ \\
\hline 1 & 5 & 439,4 \\
\hline 2 & 10 & 450,2 \\
\hline 3 & 15 & 467,3 \\
\hline 4 & 20 & 497,1 \\
\hline 5 & 25 & 530,4 \\
\hline 6 & 30 & 570,5 \\
\hline 7 & 35 & 720,2 \\
\hline 8 & 40 & 740,4 \\
\hline 9 & 45 & 840,5 \\
\hline
\end{tabular}

Tabel 6. Temperatur rata-rata burner dengan variasi percobaan A2-B3

\begin{tabular}{ccc}
\hline Percobaan & $\begin{array}{c}\text { Waktu } \\
\text { (menit) }\end{array}$ & $\begin{array}{c}\text { Temperatur } \\
\text { rata-rata } \\
\text { burner } \\
\left({ }^{\circ} \mathrm{C}\right)\end{array}$ \\
\hline 1 & 5 & 675,2 \\
\hline 2 & 10 & 689,5 \\
\hline 3 & 15 & 760,5 \\
\hline 4 & 20 & 798,3 \\
\hline 5 & 25 & 840,2 \\
\hline 6 & 30 & 892,6 \\
\hline 7 & 35 & 966,2 \\
\hline 8 & 40 & 1009,3 \\
\hline 9 & 45 & 1021,5 \\
\hline
\end{tabular}

Dari data temperatur tungku burner diatas dari variasi percobaan A1-B1 debit bahan bakar $0,00408 \mathrm{l} / \mathrm{s}$ dan kecepatan udara 10,4 $\mathrm{m} / \mathrm{s}$ didapat temperatur pada waktu 5 menit setelah burner menyala dengan stabil lalu dilakukan proses pengukuran suhu awal yang mencapai $439,4^{\circ} \mathrm{C}$. Selanjutnya pada waktu 30 menit kenaikan temperatur burner mencapai $570,5^{\circ} \mathrm{C}$ dan temperatur tertinggi mencapai $840,5^{\circ} \mathrm{C}$. Dari variasi percobaan tersebut suhu maksimal yang didapat $840,5^{\circ} \mathrm{C}$ dan suhu terendah dicapai pada menit awal yaitu 
$439,4^{\circ} \mathrm{C}$ sedangkan data temperatur tungku burner diatas dari variasi percobaan A2-B3 debit bahan bakar $0,00838 \mathrm{l} / \mathrm{s}$ dan kecepatan udara $14,3 \mathrm{~m} / \mathrm{s}$ didapat temperatur pada waktu 5 menit setelah burner menyala dengan stabil lalu dilakukan proses pengukuran suhu awal yang mencapai $675,2^{\circ} \mathrm{C}$.

Selanjutnya pada waktu 30 menit kenaikan temperatur burner mencapai $892,6^{\circ} \mathrm{C}$ dan temperatur tertinggi mencapai $1021,5^{\circ} \mathrm{C}$. Dari variasi percobaan tersebut suhu maksimal yang didapat $1021,5^{\circ} \mathrm{C}$ dan sedangkan suhu terendah dicapai pada menit awal yaitu $675,2^{\circ} \mathrm{C}$.

Pengujian incinerator dilakukan pada sampah daun kering dengan berat $8 \mathrm{~kg}$ dengan dimensi ruang pembakaran $580 \mathrm{~mm} \times 930 \mathrm{~mm}$ selama 20 menit dilakukan sebanyak 3 kali percobaan dengan konsumsi bahan bakar 0,4 liter. Adapun data pengukuran temperatur pembakaran sampah daun kering ialah sebagai berikut :

Tabel 7. Data pengukuran suhu tertinggi tungku burner dan ruang chamber pada pengujian ke 1 sampai 3 sampah daun kering

\begin{tabular}{cccc}
\hline \multicolumn{4}{c}{ Pengujian percobaan sampah daun kering } \\
\hline $\begin{array}{c}\text { Percobaan } \\
\text { ke }\end{array}$ & Waktu & $\begin{array}{c}\text { Temperatur } \\
\text { Burner } \\
\left({ }^{\circ} \mathrm{C}\right)\end{array}$ & $\begin{array}{c}\text { Temperatur } \\
\text { Chamber } \\
\left({ }^{\circ} \mathrm{C}\right)\end{array}$ \\
\hline $\mathbf{1}$ & $\begin{array}{c}20 \\
\text { menit }\end{array}$ & 689,2 & 430,6 \\
\hline $\mathbf{2}$ & $\begin{array}{c}20 \\
\text { menit }\end{array}$ & 705,3 & 421,3 \\
\hline $\mathbf{3}$ & $\begin{array}{c}20 \\
\text { menit }\end{array}$ & 712,3 & 443,2 \\
\hline
\end{tabular}

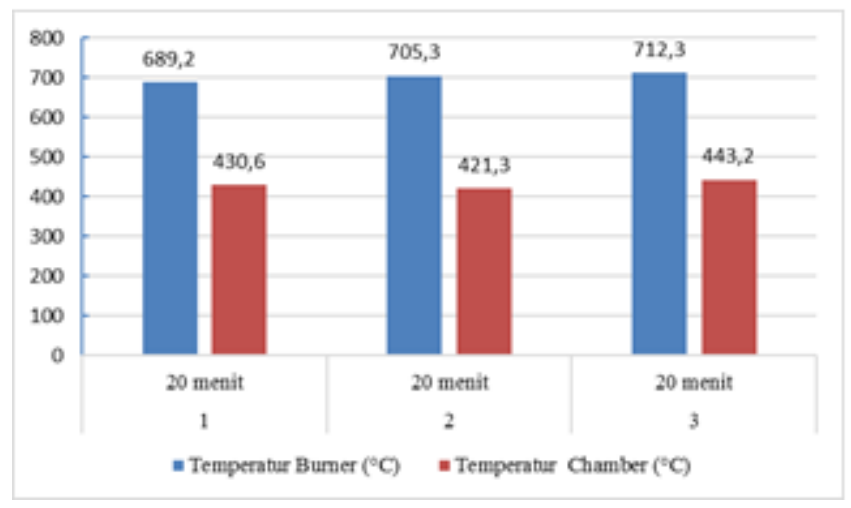

Gambar 3. Grafik temperatur tertinggi tungku burner dan ruang chamber sebanyak 3 kali pengujian.
Dari 3 kali pengujian pada ruang pembakaran incinerator menggunakan sampah daun kering abu yang dihasilkan $0,2 \mathrm{~kg}(0,33$ jam $)$ dan arang $0,045 \mathrm{~kg}$ kemudian waktu pembakaran 20 menit. Adapun perhitungan parameter uji kerja incinerator ialah sebagai berikut :

a. Laju pembakaran

$$
\mathrm{Bbt}=\frac{8 \mathrm{Kg}}{0,33 \mathrm{Jam}}=24,24 \mathrm{~kg} / \mathrm{jam}
$$

b. Rendemen $\mathrm{Abu}$

Rendemen $\mathrm{Abu}(\%)=\frac{0,2 \mathrm{~kg}}{8 \mathrm{~kg}} \times 100 \%$

Rendemen $\mathrm{Abu}(\%)=2,5 \%$

c. Rendemen Arang

Rendemen Arang (\%) $=\frac{0,045 \mathrm{~kg}}{8 \mathrm{~kg}} \times 100 \%$

Rendemen Arang (\%) $=0,56 \%$

d. Konsumsi Bahan Bakar

Fuel Consumption $(\mathrm{FC})=3$ liter $-2,6$ liter

e. Efesiensi Alat Incinerator

$$
=0,4 \text { liter }
$$

Pada proses pengujian sampah daun kering didapat efesiensinya sebagai berikut :

Efesiensi alat incinerator (\%)

$=100 \%-(0,56 \%+2,5 \%)$

Efesiensi alat incinerator (\%)

$=100 \%-3,06 \%$

Efesiensi alat incinerator $(\%)=96,94 \%$

\section{Kesimpulan}

Berdasarkan hasil percobaan temperatur tertinggi tungku burner yaitu $1021,5^{\circ} \mathrm{C}$ pada variasi percobaan A2-B3 di waktu 45 menit dengan kecepatan udara $14,3 \mathrm{~m} / \mathrm{s}$ dan laju aliran massa dari bahan bakar 7,27384 x $10^{-3}$ $\mathrm{kg} / \mathrm{s}$. Pada pengujian pembakaran sampah daun kering dengan berat $12 \mathrm{~kg}$ sampah habis terbakar pada waktu 20 menit dengan temperatur tungku burner sebesar $712,3^{\circ} \mathrm{C}$ dan temperatur ruang pembakaran incinerator $443,2^{\circ} \mathrm{C}$ dengan konsumsi bahan bakar 0,4 liter dan laju pembakaran didapatkan dari berat sampah $8 \mathrm{~kg}$ yaitu $24,24 \mathrm{~kg} / \mathrm{jam}$ dan rendemen 
sisa pembakaran yaitu 3,06 \% dan efesiensi pembakaran incinerator sebesar 96,94\%.

\section{Daftar Pustaka}

Jamaluddin. (2016, January 12). Balai Besar Pelatihan Pertanian. Retrieved from Jangan Membakar Sampah: www.BBPP-Batangkaluku.com

Kurdi, M. Y. (2017). Depok Bebas Sampah. Retrieved Maret Selasa, 2020, from https://depokbebassampah.wordpress.c om/acuan/incenerator/

Latief, A. S. (2010). Manfaat dan Dampak Penggunaan Insinerator Terhadap Lingkungan. Jurnal Tenik Mesin Politeknik Negri Semarang, 5(1), 20.

Lolo, D. P. (2014). Analisis Penggunaan Incinerator Pada Pengolahan Sampah Di Kota Merauke. Jurnal Teknik MUSTEK ANIM HA VOL 3, 200-211.

Margono, \& Rahardjo, H. P. (2011). Rancang Bangun Prototipe Tungku Pembakar Sampah Radioaktif. Jurnal Perangkat Nuklir Vol 5, 1-8.

Nurhayati, N. (2013). Pencemaran Lingkungan. Bandung: Yrama Widya.

Raharjo, W. P. (2009). Pemanfaatan Oli Bekas Dengan Pencampuran Minyak Tanah Sebagai Bahan Bakar Pada Automizing Burner. Publikasi Ilmiah, 10(2), 2.

Ratman, C. R., \& Syafrudin. (2007). Penerapan Pengelolaan Limbah B3 Di PT. Toyota Motor Manufacturing Indonesia. Jurnal Presipitasi Vol 7, 62-70.

Sumingkrat, \& Yusuf, A. (2014). Penogolahan Limbah Cair Dengan Limbah Padat Abu Hasil Pembakaran Incinerator Klor Alkali. Jurnal Teknologi Dan Manajemen Vol 12 No 1.

Supriyanto, B. (2007). Pengaruh Kecepatan Udara Terhadap Pembakaran Oli Bekas Menggunakan Automizing Burner Untuk Peleburan Alumunium. Surakarta: Skripsi S1 Teknik Mesin FT UNS

Widhiasto, R. (2010). Pengaruh Tekanan Udara Terhadap Sifat Pembakaran Minyak Jelantah Menggunakan Vaporizing Burner Untuk Peleburan Alumunium. Surakarta: Skripsi S1 Teknik Mesin Universitas Sebelas Maret Surakarta. 